\title{
Impact of off-pump coronary artery bypass grafting on long-term percutaneous coronary interventions
}

\author{
Fabio Barili, MD, PhD, ${ }^{a}$ Stefano Rosato, MSc, ${ }^{b}$ Paola D'Errigo, MSc, ${ }^{\text {b }}$ Alessandro Parolari, MD, PhD, \\ Danilo Fusco, PhD,${ }^{\mathrm{d}}$ Carlo Alberto Perucci, MD, PhD, ${ }^{\mathrm{d}}$ Lorenzo Menicanti, $\mathrm{MD},{ }^{\mathrm{e}}$ and \\ Fulvia Seccareccia, $\mathrm{MSc}^{\mathrm{b}}$
}

\begin{abstract}
Objectives: The debate regarding the advantages and limitations of off-pump versus on-pump coronary artery bypass grafting $(\mathrm{CABG})$ has yet to be resolved. This study was designed to compare the impact of surgical technique on long-term mortality and subsequent revascularization.
\end{abstract}

Methods: The Predicting Long-Term Outcomes After Isolated Coronary Artery Bypass Surgery (PRIORITY) project was designed to evaluate the long-term outcomes of 2 large, prospective multicenter cohort studies on CABG conducted in Italy between 2002 and 2004 and in 2007 and 2008. Clinical data on isolated CABG were compiled from 2 administrative databases.

Results: The study population consisted of 11,021 patients who underwent isolated CABG (27.2\% off-pump CABG). Surgical strategy did not affect in-hospital mortality. Multivariate logistic regression demonstrated that onpump CABG was the only factor that protected from in-hospital percutaneous coronary intervention after surgery (odds ratio, 0.61). Although unadjusted long-term survival was significantly worse for off-pump CABG, adjustment did not confirm off-pump CABG as a risk factor for mortality (hazard ratio, $0.96 ; 95 \%$ confidence interval, 0.87-1.06). The on-pump CABG group had a significantly lower hospitalization for subsequent percutaneous coronary intervention, a finding confirmed even with adjustment for confounding factors (hazard ratio, 0.70; 95\% confidence interval, 0.62-0.80; $P<.001$ ). Offpump CABG thus carried a $42 \%$ higher risk for subsequent percutaneous coronary intervention than on-pump CABG. The incidence of repeat CABG was similar between groups.

Conclusions: This study demonstrated that off-pump OPCAB did not affect short- and long-term mortality, but it was a significant risk factor for rehospitalization for percutaneous coronary intervention. (J Thorac Cardiovasc Surg 2015;150:902-9)

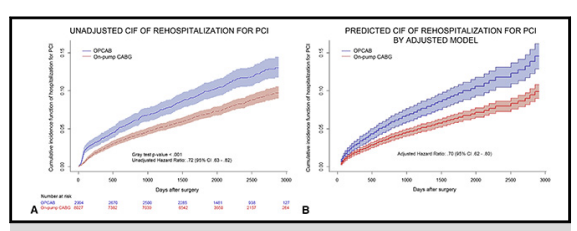

Unadjusted and adjusted cumulative incidence function (CIF) of hospitalization for percutaneous coronary intervention $(P C)$ after off-pump (OPCAB) and onpump coronary artery bypass grafting $(C A B G)$.

\section{Central Message}

Off-pump coronary artery bypass grafting does not affect long-term mortality, but it is associated with a higher risk of rehospitalization for percutaneous coronary intervention at 8 years.

\section{Perspective}

The debate regarding the advantages and disadvantages of off-pump coronary artery bypass grafting persists, and few studies with longterm follow-up data are available. This study shows that off-pump coronary artery bypass grafting exposes patients to an increased risk of repeated revascularization as late as 8 years, with potential adverse long-term clinical outcomes and important implications for health resources allocation.

See Editorial Commentary page 909.

\footnotetext{
From the ${ }^{a}$ Department of Cardiac Surgery, S. Croce Hospital, Cuneo, Italy; the ${ }^{b}$ National Centre for Epidemiology, Surveillance and Health Promotion, Istituto Superiore di Sanità, Rome, Italy; the ${ }^{\mathrm{c} U n i t}$ of Cardiac Surgery and Translational Research, IRCCS Policlinico S. Donato, S. Donato Milanese, Italy; ${ }^{\mathrm{d}}$ Department of Epidemiology, Regional Health Service, Lazio Region, Rome, Italy; and the ${ }^{\mathrm{e}}$ Unit of Cardiac Surgery, IRCCS Policlinico S. Donato, University of Milan, Milanese, Italy.

F.B and S.R. contributed equally to this article. L.M. and F.S. are equal senior authors. Received for publication Feb 9, 2015; revisions received June 17, 2015; accepted for publication July 2, 2015; available ahead of print Aug 12, 2015.

Address for reprints: Fabio Barili, MD, PhD, Department of Cardiac Surgery, S. Croce Hospital, Via M. Coppino 26, 12100 Cuneo, Italy (E-mail: fabarili@ libero.it or barili.f@ospedale.cuneo.it).

$0022-5223 / \$ 36.00$

Copyright (C) 2015 by The American Association for Thoracic Surgery

http://dx.doi.org/10.1016/j.jtcvs.2015.07.018
}

๑ Supplemental material is available online.

The debate regarding the advantages and limitations of offpump coronary artery bypass grafting (OPCAB) versus onpump coronary artery bypass grafting (CABG) has not been resolved, although there have been a number of clinical trials published on this very issue. ${ }^{1}$ Several randomized and observational studies have previously suggested that OPCAB may be associated with less morbidity and better short-term outcome, especially with regard to the incidence of postoperative atrial fibrillation, neurologic events, blood product 


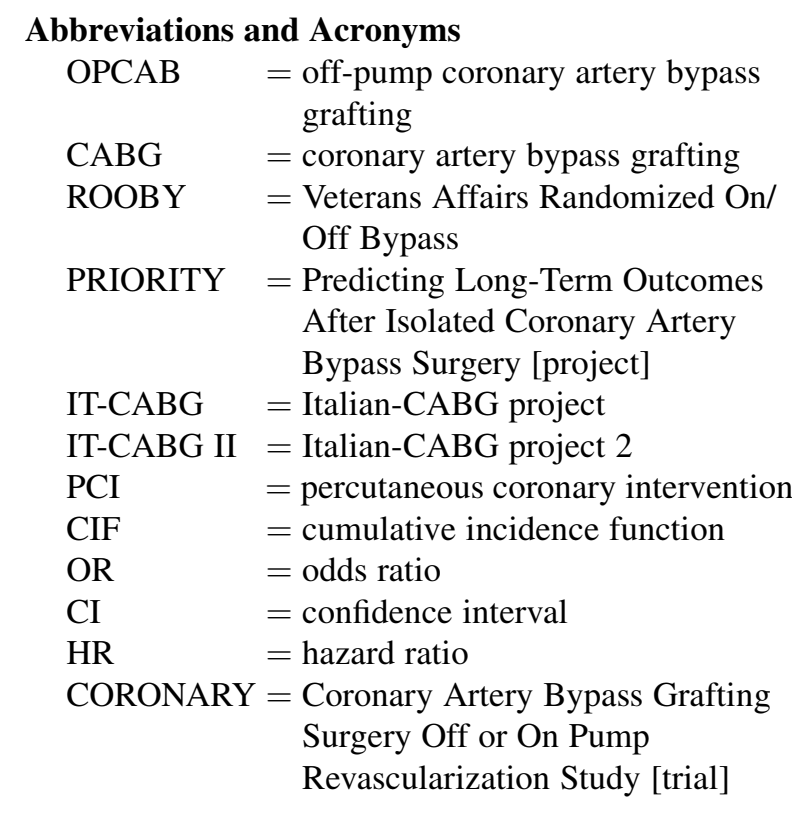

transfusion rate, and perioperative mortality. ${ }^{2-13}$ These results have not been widely validated, ${ }^{14-16}$ however, and the lack of obvious benefit for OPCAB has been made pronounced by the demonstration of better composite outcomes with the use of extracorporeal circulation. ${ }^{17,18}$

The completeness of revascularization and patency of grafts have emerged as the primary concerns for OPCAB procedures. Patients treated with OPCAB were more likely to have fewer than planned bypass grafts in the Veterans Affairs Randomized On/Off Bypass (ROOBY) trial, ${ }^{19}$ an observation that has been confirmed by other studies evaluating multivessel disease, ${ }^{20}$ although no significant differences in rate of revascularization were demonstrated in low-risk patients who required only 1 or 2 grafts. ${ }^{21}$ OPCAB has also been shown to have lower patency rates of arterial and saphenous grafts in randomized studies, ${ }^{19,21-23}$ as well as a higher incidence of repeated revascularization at 3 years in a large observational study. ${ }^{24}$ Conversely, several observational reports have demonstrated excellent patency rates for OPCAB in patients with single- or double-vessel disease and with a lower proportion requiring circumflex artery grafts. ${ }^{10,25,26}$ The primary limitation with current literature is the lack of long-term outcomes beyond 1 to 3 years.

The Predicting Long-Term Outcomes After Isolated Coronary Artery Bypass Surgery (PRIORITY) project was developed through a collaboration between the National Centre for Epidemiology, Surveillance and Health Promotion of the Italian National Institute of Health and the Italian Society of Cardiac Surgery. It specifically sought to analyze the long-term outcomes from 2 prospective multicenter cohort studies conducted between 2002 and 2008 to assess shortterm outcomes of patients undergoing isolated CABG in
Italy. ${ }^{27-31}$ The main objective of the PRIORITY project was to identify potential tools for quality control that could lead to improvements in the standard of care and better allocation of economical resources. ${ }^{27,28}$ In this context, the evaluation of hospitalization for repeated coronary revascularization represents a central issue for both clinical and health management. The analysis of long-term efficacy of the $2 \mathrm{CABG}$ techniques might clarify and consolidate the contrasting literature on short-term outcomes. This study was undertaken to analyze both long-term mortality and incidence of rehospitalization for repeated revascularization as possible consequences of surgical technique.

\section{MATERIALS AND METHODS}

\section{Study Design and Study Data Set}

PRIORITY is an observational prospective cohort study. This analysis was designed by the PRIORITY planning committee to evaluate longterm follow-up of isolated CABG performed in both on-pump and offpump fashion. The sources of all individual clinical data were 2 large, prospective, multicenter cohort studies conducted in 2002 through 2004 (Italian-CABG project, IT-CABG; Appendix E1) and 2007 and 2008 (Italian-CABG project 2, IT-CABG II; Appendix E2). ${ }^{29-31}$ The 2 studies used the same data set. The common template contains information regarding demographics, preoperative risk factors made uniform by euroSCORE definitions, surgical procedures including the use of extracorporeal circulation, complications, date of admission, surgery, discharge date, and discharge disposition. The IT-CABG and IT-CABG II studies were previously approved by the Institutional Ethical Committees, and the requirement for informed written consent was waived on the condition that subjects' identities remain masked. The institutional review boards approved the clinical data set's use for research.

Follow-up information was obtained by matching clinical data with 2 national administrative databases, the Italian Hospital Discharge Register and the Tax Register Information System. The Italian Hospital Discharge Register provided information on patient hospitalization, with a focus on readmission for percutaneous coronary intervention (PCI) or repeat CABG. The Tax Register provided patient status (dead vs alive) and date of event or censoring. The methodologies used for record-linkage among databases have been previously described. ${ }^{32}$ Tax Register data linked with the Italian Hospital Discharge Register were available only from the beginning of 2004, therefore, patients enrolled in IT-CABG before December 31, 2003, were excluded. The study population included all patients who underwent isolated CABG, were enrolled within the 2 IT-CABG studies after January 1, 2004, and whose information was matched with the 2 administrative databases. Follow-up was truncated at December 31, 2012; patients who did not have the events were considered as rightcensored.

\section{Data Analysis}

In-hospital and postdischarge events were analyzed separately.

In-hospital events were treated as dichotomous variables, occurring in a short time frame, and the evaluation of potential risk factors was performed by means of logistic regression analysis.

After discharge, the primary events were managed as time to event data and analyzed with nonparametric and semiparametric methods. Discharge date from the hospital was defined as the beginning of follow-up period, and all intraoperative deaths were excluded from time to event analysis. Crude mortalities at predefined time points ( 30 days to 8 years) were estimated by the Kaplan-Meier method; occurrence of PCI rates at the same time points were estimated by the cumulative incidence function (CIF) of the first PCI after CABG, with death as competing risk. 
TABLE 1. Descriptive statistics of the study group and of the off-pump and on-pump coronary artery bypass grafting subgroups

\begin{tabular}{|c|c|c|c|c|}
\hline Preoperative data and comorbidities & Study group $(n=11,021)$ & Off-pump $(n=2994)$ & On-pump $(n=8027)$ & $P$ value \\
\hline $\operatorname{Age}(y$, mean $\pm S E)$ & $67.1 \pm 9.5$ & $67.8 \pm 10.0$ & $66.8 \pm 9.3$ & $<.001$ \\
\hline Female sex (No. and \%) & $2159(19.6 \%)$ & $607(20.3 \%)$ & $1552(19.3 \%)$ & .27 \\
\hline Creatininemia $>2 \mathrm{mg} / \mathrm{dL}$ (No. and \%) & $511(4.6 \%)$ & $188(6.3 \%)$ & $323(4.0 \%)$ & $<.001$ \\
\hline Dialysis (No. and \%) & $87(0.8 \%)$ & $33(1.1 \%)$ & $54(0.7 \%)$ & .02 \\
\hline Diabetes (requiring drug treatment; No. and \%) & $3560(32.3 \%)$ & $1002(33.5 \%)$ & $2558(31.9 \%)$ & .11 \\
\hline Neurologic dysfunction* (No. and \%) & $203(1.9 \%)$ & $69(2.3 \%)$ & $134(1.7 \%)$ & .02 \\
\hline Previous stroke (No. and \%) & $370(3.3 \%)$ & $120(4.0 \%)$ & $250(3.1 \%)$ & .01 \\
\hline $\begin{array}{l}\text { Pulmonary hypertension (systolic pulmonary arterial } \\
\text { pressure }>60 \mathrm{~mm} \mathrm{Hg}^{*} ; \text { No. and \%) }\end{array}$ & $41(0.4 \%)$ & $13(0.4 \%)$ & $28(0.3 \%)$ & .52 \\
\hline Chronic pulmonary disease* (No. and \%) & $1033(9.4 \%)$ & $473(15.8 \%)$ & $560(7.0 \%)$ & $<.001$ \\
\hline Cancer (No. and \%) & $118(1.1 \%)$ & $64(2.1 \%)$ & $54(0.7 \%)$ & $<.001$ \\
\hline Extracardiac arteriopathy* (No. and \%) & $2187(19.8 \%)$ & $657(21.9 \%)$ & $1530(19.1 \%)$ & $<.001$ \\
\hline Cirrhosis (No. and \%) & $30(0.3 \%)$ & $13(0.4 \%)$ & $17(0.2 \%)$ & .04 \\
\hline Unstable angina (No. and \%) & $2919(26.5 \%)$ & $875(29.2 \%)$ & $2044(25.5 \%)$ & $<.001$ \\
\hline Recent myocardial infarction* (No. and \%) & $2781(25.2 \%)$ & $697(23.3 \%)$ & $2084(26.0 \%)$ & .004 \\
\hline Left ventricular ejection fraction $<30 \%$ (No. and $\%$ ) & $264(2.4 \%)$ & $82(2.7 \%)$ & $182(2.3 \%)$ & .19 \\
\hline Previous CABG (No. and \%) & $224(2.0 \%)$ & $81(2.7 \%)$ & $143(1.8 \%)$ & .002 \\
\hline Previous cardiac surgery excluding CABG (No. and \%) & $100(0.9 \%)$ & $30(1.0 \%)$ & $70(0.9 \%)$ & .52 \\
\hline Hemodynamic instability $\dagger$ (No. and \%) & $588(5.3 \%)$ & $260(8.7 \%)$ & $328(4.1 \%)$ & $<.001$ \\
\hline Recent ventricular arrhythmia $\ddagger$ (No. and \%) & $252(2.3 \%)$ & $64(2.1 \%)$ & $188(2.3 \%)$ & .56 \\
\hline Cardiogenic shock (No. and \%) & $84(0.8 \%)$ & $19(0.6 \%)$ & $65(0.8 \%)$ & .35 \\
\hline Emergency status of operation* (No. and \%) & $404(3.7 \%)$ & $123(4.1 \%)$ & $281(3.5 \%)$ & .14 \\
\hline
\end{tabular}

$\overline{S E}$, Standard error; $C A B G$, coronary artery bypass grafting. *As defined by the euroSCORE. †Preoperative inotropic support or intra-aortic balloon pump. $\ddagger$ Preoperative recurrent ventricular tachycardia or ventricular fibrillation.

Time to event distributions were separately analyzed accordingly to primary event type (death, first rehospitalization for PCI, first rehospitalization for repeated CABG) with Kaplan-Meier estimates and Cox regression used for time to death analysis. Fine and Gray models were used in competing risk analysis for time to PCI and time to repeat $\mathrm{CABG}$, with death as competing risk. The variables selection for the Cox models was performed by a forward stepwise linear regression (probability of stay $=.10$; probability of entry $=.05$ ). The variable selection for the Fine and Gray models was performed by a forward stepwise regression with the Akaike information criterion as selection criteria. For time to PCI and time to repeated $\mathrm{CABG}$, nonparametric analyses of the outcome variables of interest were computed with the CIF, and subdistribution hazards and comparisons were computed by means of Fine and Gray test. Direct regression modeling of the effect of covariates on CIF was performed through the semiparametric proportional hazard model for the subdistribution hazards proposed by Fine and Gray, allowing for time-varying effect of the covariates. ${ }^{33-35}$ Hazards proportionality and time-dependent effects were checked with the analysis of Shoenfeld residuals, the KolmogorovSmirnov test, and the Cramer von Mises test.

The relationship between outcomes and surgical technique was also explored with the propensity score approach. The probability of a patient undergoing $\mathrm{OPCAB}$ was generated by a nonparsimonious logistic regression model (21 baseline variables). The logit of the resulting propensity score was used to match pairs of OPCAB and on-pump CABG patients, with the greedy matching algorithm (caliper 0.01 of the standard deviation of the logit of the propensity score). To evaluate the balance between the matched groups the standardized differences and the following tests were used: $t$ test for paired sample for continuous variables, McNemar test for dichotomous variables, and Stuart-Maxwell test for categoric variables (see Table E4). Long-term mortality in the propensity score-matched populations were compared by the Kaplan-Meier method with the KleinMoeschberger stratified log-rank test; the PCI CIFs were compared by the Gray test.

Two-sided statistics were performed. For all analyses, we used SAS version 9.2 (SAS Institute, Cary, NC) and R 3.0.3 software (R Development
Core Team [2014]. R: A language and environment for statistical computing. R Foundation for Statistical Computing, Vienna, Austria. ISBN 3-900051-07-0, URL http://www.R-project.org/).

\section{RESULTS}

The IT-CABG and IT-CABG II studies enrolled 34,313 and 7433 patients, respectively, for a total of 41,746 patients overall; 11,538 patients $(27.6 \%)$ were enrolled after January 1, 2004, and had administrative data available for linkage. The record linkage of administrative and clinical data sets led to $95.5 \%$ linkage. The final study cohort therefore comprised 11,021 patients with complete clinical perioperative data and administrative follow-up. Of these, 2994 $(27.2 \%)$ were in the OPCAB group and 8027 (72.8\%) were in the on-pump CABG group.

Table 1 shows the baseline characteristics of the study groups. The preoperative risk profile was higher for OP$\mathrm{CAB}$ patients, as they were significantly older and had a higher prevalence of comorbidities. OPCAB was preferred for patients with significant chronic pulmonary disease, renal dysfunction, cirrhosis, active neoplastic disease, previous stroke, and extracardiac arteriopathy. The cardiac profiles of the 2 groups were similar with regard to emergency status, cardiogenic shock, and low left ventricular ejection fraction. Patients in the OPCAB group were more likely to have symptoms (unstable hemodynamic status and angina) and had a higher incidence of previous CABG, whereas on-pump CABG was performed more frequently on patients with recent myocardial infarction. 
UNADJUSTED SURVIVAL ESTIMATES

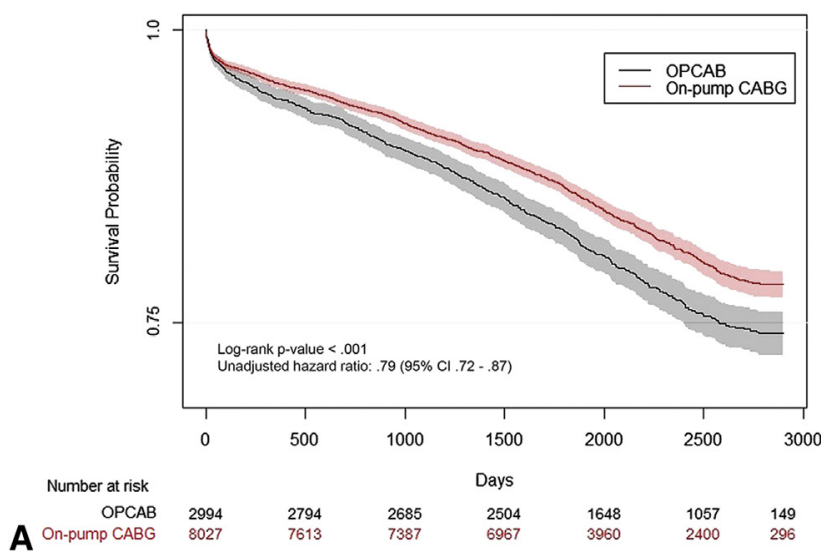

PREDICTED SURVIVAL BY ADJUSTED MODEL

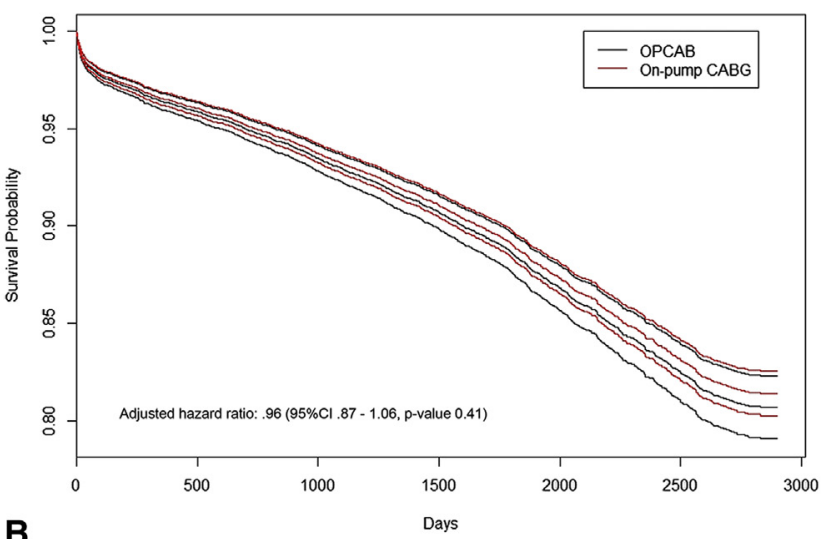

FIGURE 1. A, Unadjusted Kaplan-Meier estimates of long-term survival (out to 8 years). B, Predicted Kaplan-Meier estimates of long-term survival with $95 \% \mathrm{CI}$ for each group according to the adjusted model. The surgical technique (OPCAB or on-pump CABG) was not associated with increased long-term mortality, as the adjusted hazard ratio was $0.96 \pm 0.05$ ( $95 \%$ confidence interval, $0.87-1.06 ; P=.41)$. OPCAB, Off-pump coronary artery bypass grafting; $C A B G$, coronary artery bypass grafting; $C I$, confidence interval.

\section{In-Hospital Mortality and Morbidity}

Two hundred twenty-two patients $(2.0 \%)$ died during their primary hospitalization, with no differences between the 2 groups $(P=.73)$. With multivariate logistic regression, several risk factors independently affected in-hospital mortality, but these did not include surgical technique (Table E1).

The number of in-hospital postoperative PCI procedures was 158 , and postoperative PCI was significantly more common in the OPCAB group than in the on-pump CABG group $(2.64 \%$ vs $0.98 \% ; P<.001)$. The stepwise multivariate logistic regression analysis showed that the use of extracorporeal circulation was the only factor associated with a reduction in in-hospital postoperative PCI (odds ratio [OR], 0.37; 95\% confidence interval [CI], 0.27-0.51).

\section{Long-Term Outcomes}

Crude mortalities at 30 days and at 8 years for OPCAB versus on-pump CABG were $2.2 \%$ versus $2.0 \%$ and $23.5 \%$ versus $20.2 \%$, respectively. Postdischarge PCI rates at 30 days and at 8 years for OPCAB versus on-pump CABG were $0.3 \%$ versus $0.1 \%$ and $14.3 \%$ versus $12.0 \%$, respectively. Table E2 shows crude mortalities and first PCI rates for other predefined time points.

Figure 1, A, shows the Kaplan-Meier estimates for the long-term survival curves on the basis of 60,788.21 patient-years of follow-up (median follow-up of 5.5 years). The difference between OPCAB and on-pump CABG curves was significant (log-rank $P<.001)$. The unadjusted hazard ratio (HR) for death was 0.79 (95\% CI, 0.72-0.87; $P<.001$ ), in favor of on-pump CABG. The adjusted HR was 0.96 (95\% CI, 0.87-1.06; $P .41)$, however, thereby disassociating surgical technique with increased long-term mortality (Table E3). The long-term predicted survival curves with $95 \% \mathrm{CI}$, according to the adjusted model, are shown in Figure 1, $B$.

Figure 2, $A$, reports the CIFs of the first rehospitalization for PCI in the 2 groups, with death as a competing risk. The difference between OPCAB and on-pump CABG was significant (Gray test $P<.001$ ). The unadjusted HR for time to PCI was $0.72(95 \% \mathrm{CI}, 0.63-0.82, P<.001)$, with $\mathrm{OPCAB}$ as the reference group. After adjustment for the variables listed in Table 2, the adjusted HR was similar (adjusted HR, 0.70; 95\% CI, 0.62-0.80; $P<.001$ ), supporting on-pump $\mathrm{CABG}$ as a negative risk factor for rehospitalization for PCI at follow-up. The assumption of hazard-proportionality was considered fulfilled on the basis of the analysis of Shoenfeld residuals and the tests for time-invariant effect (KolmogorovSmirnov test and Cramer von Mises test; $P=.27$ and $P=.36$, respectively). Thus on-pump CABG qualified as an independent protective factor for recurrent PCI after CABG. The long-term predicted CIFs with $95 \%$ CIs derived from the adjusted Fine and Gray model are shown in Figure 2, B. Although the protective effect of on-pump $\mathrm{CABG}$ on rehospitalization for PCI could be considered constant by the Kolmogorov-Smirnov and Cramer von Mises tests, the analysis of hazard risk trend in fact showed a time effect in the first 2 years, with progressive decrease in benefit and a stabilization of the HR to a constant value after 2 years (Figure 3). Among other regressors found significant in multivariate analysis, all but female sex and previous CABG reduced the risk of hospitalization for PCI $(\mathrm{HR}<1)$, suggesting that the presence of other comorbidities and older age may have led to more conservative management strategies (Table 2).

There was no significant difference in the incidence of repeated CABG between the OPCAB and on-pump CABG groups (10 [0.33\%] vs 29 [0.36\%], respectively; 

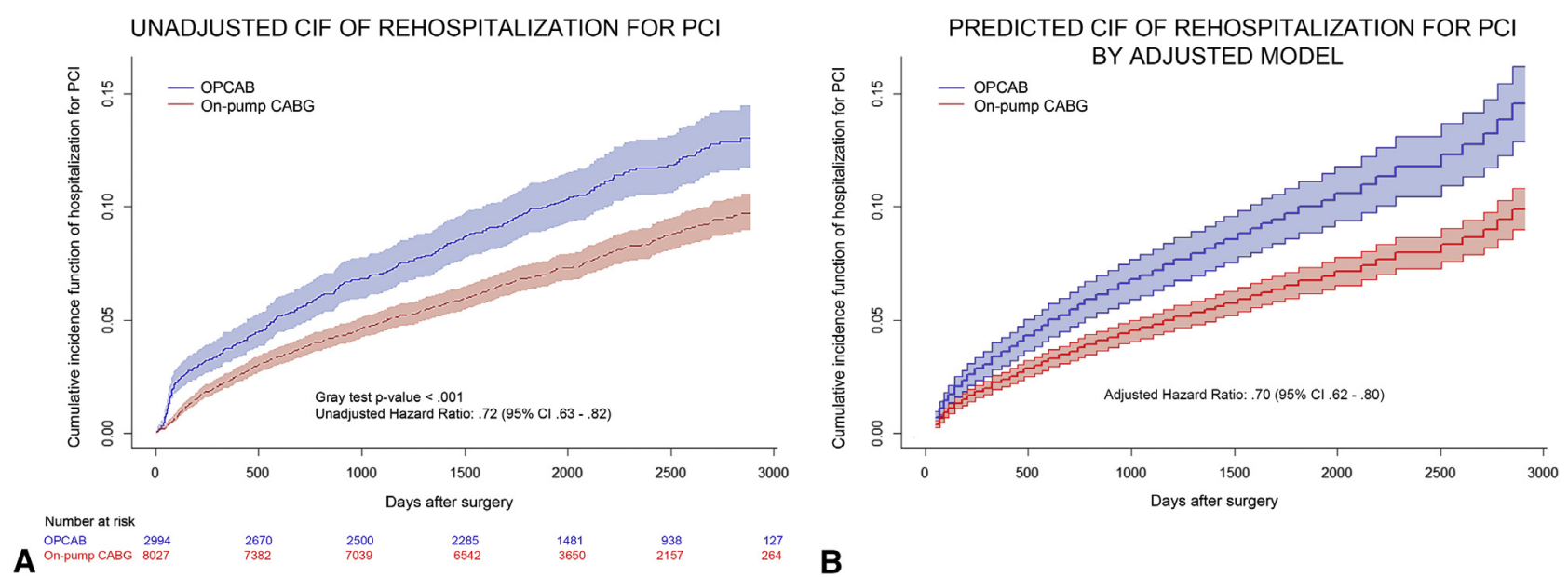

B

FIGURE 2. A, Unadjusted CIF of hospitalization for PCI after CABG in each group, with death as a competing risk. The difference between off-pump and on-pump CABG was significant (Gray test $P<.001$ ). B, Predicted cumulative incidence function estimates of rehospitalization for percutaneous coronary intervention for each group according to the adjusted model. The adjusted cumulative incidence functions and hazard ratio did not differ from the unadjusted ones. $C I F$, Cumulative incidence function; $P C I$, percutaneous coronary intervention; $O P C A B$, off-pump coronary artery bypass grafting; $C A B G$, cononary artery bypass grafting; $C I$, confidence interval.

$\chi^{2}$ test $\left.P=.9\right)$. The nonparametric CIFs of the first hospitalization for repeated $\mathrm{CABG}$, with death as a competing risk, were also similar between the 2 groups (Gray test $P=.6$ ).

Propensity score matching produced a well-balanced cohort of 2739 patients in the OPCAB group $(91.5 \%)$ and 2739 patients in the on-pump CABG group (Table E4 and Figure E1). The postmatching analysis confirmed the results of the multivariate regression. Figure E2 shows the Kaplan-Meier estimates of survival curves in the 2 matched groups. The difference between OPCAB and on-pump $\mathrm{CABG}$ curves was not significant (Klein-Moeschberger $\log$-rank test $P>.05$ ). Figure E3 reports the CIFs of the first rehospitalization for PCI in the 2 matched groups, with death as a competing risk. The difference between OPCAB and on-pump CABG was significant (Gray test $P<.001$ ). The adjusted HR was 0.70, in favor of on-pump CABG, even with propensity score matching.

\section{DISCUSSION}

The complex debate regarding off-pump versus onpump CABG persists, with both operative strategies

TABLE 2. Hazard ratios of the adjusted Fine and Gray model for predicting hospitalization for percutaneous coronary intervention after surgery

\begin{tabular}{lccc}
\hline \multicolumn{1}{c}{ Variable } & HR & $\begin{array}{c}\mathbf{9 5} \% \mathbf{C I} \\
\text { of } \mathbf{H R}\end{array}$ & $\begin{array}{c}\boldsymbol{P} \\
\text { value }\end{array}$ \\
\hline Age & 0.98 & $0.97-0.98$ & $<.001$ \\
On-pump CABG & 0.70 & $0.62-0.80$ & $<.001$ \\
Female sex & 1.32 & $1.13-1.54$ & $<.001$ \\
Previous CABG & 1.75 & $1.23-2.48$ & .002 \\
Left ventricular ejection fraction $<30 \%$ & 0.61 & $0.36-1.04$ & .07 \\
Emergency status & 0.72 & $0.50-1.06$ & .09 \\
\hline
\end{tabular}

$H R$, Hazard ratio; $C I$, confidence interval; $C A B G$, coronary artery bypass grafting. supported by several studies. On-pump CABG remains the preferred technique, allowing safety and reproducibility of the procedure. ${ }^{36-38}$ On the contrary, OPCAB was developed to overcome the potential complications related to cardiopulmonary bypass. These theoretic advantages led to a rapid adoption and 10-fold increase in OPCAB procedures by the mid-2000s, with the objective of improving short-term outcomes. ${ }^{2-13}$ Initial encouraging

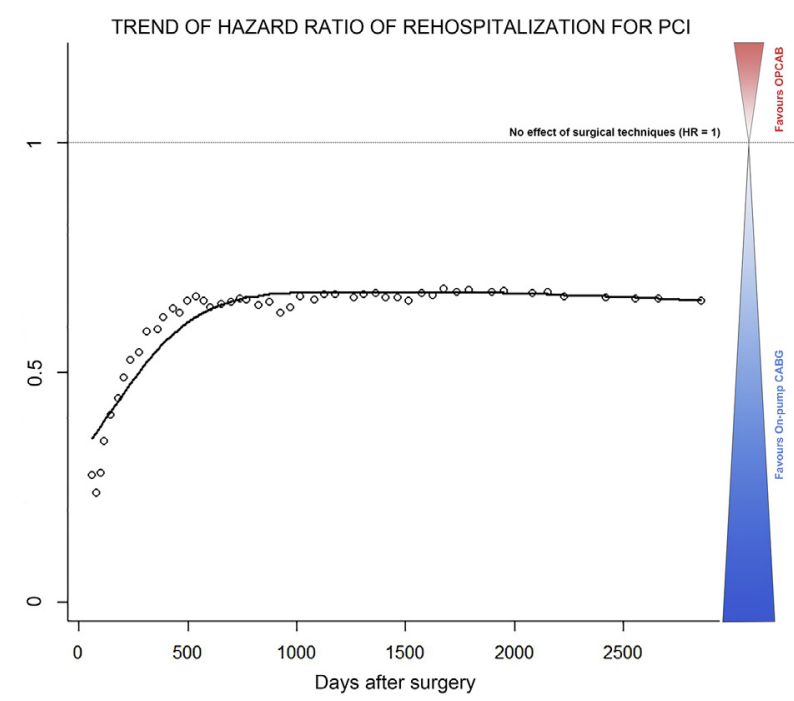

FIGURE 3. Estimates of time -varying effect of the adjusted hazard ratio of on-pump CABG versus OPCAB. Although the hazard proportionality has been respected at long-term follow-up analysis, the analysis of hazard risk trend showed a time effect in the first 2 years, with progressive decrease of the protective effect of on-pump coronary artery bypass grafting and a stabilization of the hazard ratio to a constant value (0.7). PCI, Percutaneous coronary intervention; $O P C A B$, off-pump coronary artery bypass grafting; $C A B G$, coronary artery bypass grafting. 
results were not widely confirmed, and it was postulated that the reduction of the systematic inflammatory response syndrome triggered by cardiopulmonary bypass does not, in fact, lead to better clinical outcomes. In the context of variable clinical outcomes, attention was primarily focused on more measurable outcomes, and the issues of reduced graft patency and incompleteness of revascularization emerged as potential major pitfalls of OPCAB. ${ }^{19,21-23}$ Notwithstanding, even recent randomized trials drew contrasting conclusions in the analysis of short-term outcomes, ${ }^{19,39}$ and the debate has shifted toward the surgeon's experience and its relationship with the risk of reduced graft patency. ${ }^{39}$

The major finding of this study is that OPCAB is associated with a significantly increased risk of rehospitalization for PCI, both in the perioperative setting and in long-term follow-up. These results seem to coincide with the findings of reduced effectiveness of revascularization in patients undergoing OPCAB in the ROOBY trial and in the 1-year angiographic follow-up of its cohort. ${ }^{19}$ The trend toward an increased incidence of rehospitalization for PCI has also been demonstrated in studies that criticized the ROOBY trial. Among them, the Coronary Artery Bypass Grafting Surgery Off or On Pump Revascularization Study (CORONARY) trial was designed to overcome the potential limitations of surgical experience among participants within the ROOBY trial, requiring a higher level of surgical skills among participant surgeons. ${ }^{39}$ Although Lamy and colleagues $^{39}$ reported similar singular and composite outcomes with the two surgical techniques, the difference between repeated revascularization rates trended toward statistical significance $(1.4 \%$ in OPCAB vs $0.8 \%$ in onpump CABG; $P=.07$ ) and did not differ widely from that reported in the ROOBY trial ${ }^{19}(6.3 \%$ in OPCAB vs $3.7 \%$ in on-pump CABG; $P=.03$ ).

When the data of the 2 studies are analyzed by comparison of contingency tables, a significantly higher incidence of repeat revascularization is noted in the ROOBY trial than in the CORONARY trial. These higher incidences are demonstrated not only in the OPCAB group $(1.4 \%$ in CORONARY vs $6.3 \%$ in ROOBY; $P<.001)$ but also in the on-pump group $(0.8 \%$ in CORONARY vs $3.7 \%$ in ROOBY; $P<.001)$. The quantification of the adjunctive risk of the ROOBY trial relative to the CORONARY trial by means of OR analysis shows that ORs are similar in both OPCAB (4.5) and on-pump CABG (4.8) groups. Thus the more selective qualification for surgeons in the CORONARY trial may have led to better outcomes, irrespective of operative technique, with similar reductions in repeated revascularization rates for OPCAB and on-pump $\mathrm{CABG}$, whereas the comparison between the 2 techniques did not diverge widely within the studies.

In our study, a similar protective effect of high-volume surgery was found in both OPCAB and on-pump CABG (data not shown). Few studies with follow-up beyond midterm outcomes are available. The adjusted HR for repeated PCI has been reported to be 1.5 for OPCAB relative to on-pump CABG at 3-year follow-up. ${ }^{24}$ This increased risk related to the off-pump strategy is confirmed by the outcomes of this study (HR of 1.4) at an even longer follow-up period. Our study is limited by the lack of data on completeness and effectiveness of revascularization and on eventual hybrid revascularization strategies. Nonetheless, if the higher rate of inhospital PCI is partially determined by hybrid strategies, the higher risk of rehospitalization for PCI at long-term follow-up cannot be justified by tailored revascularization strategies, and it is the proof of concept of the minor efficacy of OPCAB in achieving durable revascularization results. $^{19}$

The adjusted in-hospital and 8-year mortalities were demonstrated not to be associated with surgical technique. The unadjusted higher mortality of OPCAB reflects the different risk profiles of the 2 groups, with OPCAB procedures being performed in significantly older patients and those with a higher prevalence of comorbidities. Our findings are similar to those reported by other studies, especially with respect to short-term outcomes. ${ }^{14-19}$ Still, no shared consensus has been reached, particularly in the analysis of perioperative mortality and morbidity, and some studies have reported a lower risk of adjusted inhospital mortality in the OPCAB group. The data available on long-term mortality parallel the results of this study, which maintain that the mortality benefit of either technique relative to the other has yet to be demonstrated.

\section{Limitations}

Our study is limited by its observational nature. No inferences can be drawn on the causes for higher incidence of repeated revascularization, because no data were available on the completeness and effectiveness of revascularization. The hypothesis formulated in this discussion must therefore be taken within the context of an observational study. Moreover, the risk of selection bias could still be present for regressors that were not available in the database; the ITCABG and IT-CABG II studies were devised to evaluate perioperative outcomes, correcting mainly for factors included in euroSCORE, yet no information on details of coronary artery disease and surgical strategy was collected. Nonetheless, the study was designed to focus on the "real world" and on the potential impact of surgical techniques on long-term outcomes, and the primary finding is that OP$\mathrm{CAB}$ increases the risk of rehospitalization for repeated revascularization. The strength of this study is attributable to access to a large data set comprising more than 11,000 patients with complete clinical information and to the advantages of administrative follow-up. There were no patients unavailable for follow-up, and long-term data were 
collected independent of participating researchers and clinicians.

\section{CONCLUSIONS}

This study suggests that OPCAB does not affect short- or long-term mortality but is associated with an increased long-term risk of repeated PCI. These findings may have important implications with respect to health resources allocation, particularly in a climate of cost containment of health care expenditures.

\section{Conflict of Interest Statement}

F.B. reports receiving consulting fees from St Jude Medical. All other authors have nothing to disclose with regard to commercial support.

We sincerely thank Nicholas C. Dang (Queen's Heart Physician Practice, Honolulu, Hawaii) for his kind help and assistance in editing the manuscript.

\section{References}

1. Sellke FW, DiMaio JM, Caplan LR, Ferguson TB, Gardner TJ, Hiratzka LF, et al; American Heart Association. Comparing on-pump and off-pump coronary artery bypass grafting: numerous studies but few conclusions: a scientific statement from the American Heart Association council on cardiovascular surgery and anesthesia in collaboration with the interdisciplinary working group on quality of care and outcomes research. Circulation. 2005;111:2858-64.

2. Panesar SS, Athanasiou T, Nair S, Rao C, Jones C, Nicolaou M, et al. Early outcomes in the elderly: a meta-analysis of 4921 patients undergoing coronary artery bypass grafting-comparison between off-pump and on-pump techniques. Heart. 2006:92:1808-16.

3. Sedrakyan A, Wu AW, Parashar A, Bass EB, Treasure T. Off-pump surgery is associated with reduced occurrence of stroke and other morbidity as compared with traditional coronary artery bypass grafting: a meta-analysis of systematically reviewed trials. Stroke. 2006;37:2759-69.

4. van Dijk D, Nierich AP, Jansen EW, Nathoe HM, Suyker WJ, Diephuis JC, et al; Octopus Study Group. Early outcome after off-pump versus on-pump coronary bypass surgery: results from a randomized study. Circulation. 2001;104:1761-6.

5. Van Dijk D, Jansen EW, Hijman R, Nierich AP, Diephuis JC, Moons KG, et al; Octopus Study Group. Cognitive outcome after off-pump and on-pump coronary artery bypass graft surgery: a randomized trial. JAMA. 2002;287:1405-12.

6. Puskas JD, Williams WH, Mahoney EM, Huber PR, Block PC, Duke PG, et al Off-pump vs conventional coronary artery bypass grafting: early and 1-year graft patency, cost, and quality-of-life outcomes: a randomized trial. JAMA. 2004;291: 1841-9.

7. Cleveland JC Jr, Shroyer AL, Chen AY, Peterson E, Grover FL. Off-pump coronary artery bypass grafting decreases risk-adjusted mortality and morbidity. Ann Thorac Surg. 2001;72:1282-8; discussion 1288-9.

8. Wijeysundera DN, Beattie WS, Djaiani G, Rao V, Borger MA, Karkouti K, et al. Off-pump coronary artery surgery for reducing mortality and morbidity: metaanalysis of randomized and observational studies. J Am Coll Cardiol. 2005;46: 872-82.

9. Plomondon ME, Cleveland JC Jr, Ludwig ST, Grunwald GK, Kiefe CI, Grover FL, et al. Off-pump coronary artery bypass is associated with improved risk-adjusted outcomes. Ann Thorac Surg. 2001;72:114-9.

10. Nathoe HM, van Dijk D, Jansen EW, Suyker WJ, Diephuis JC, van Boven WJ, et al; Octopus Study Group. A comparison of on-pump and off-pump coronary bypass surgery in low-risk patients. N Engl J Med. 2003;348:394-402.

11. Lamy A, Devereaux PJ, Prabhakaran D, Taggart DP, Hu S, Paolasso E, et al. Offpump or on-pump coronary-artery bypass grafting at 30 days. N Engl J Med. 2012;366:1489-97.

12. Afilalo J, Rasti M, Ohayon SM, Shimony A, Eisenberg MJ. Off-pump vs. onpump coronary artery bypass surgery: an updated meta-analysis and metaregression of randomized trials. Eur Heart J. 2012;33:1257-67.
13. Marui A, Okabayashi H, Komiya T, Tanaka S, Furukawa Y, Kita T, et al. Benefits of off-pump coronary artery bypass grafting in high-risk patients. Circulation. 2012;126(11 Suppl 1):S151-7.

14. Légaré JF, Buth KJ, King S, Wood J, Sullivan JA, Hancock Friesen C, et al. Coronary bypass surgery performed off pump does not result in lower in-hospital morbidity than coronary artery bypass grafting performed on pump. Circulation. 2004; 109:887-92.

15. Møller CH, Perko MJ, Lund JT, Andersen LW, Kelbaek H, Madsen JK, et al. No major differences in 30-day outcomes in high-risk patients randomized to offpump versus on-pump coronary bypass surgery: the best bypass surgery trial. Circulation. 2010;121:498-504.

16. Møller CH, Penninga L, Wetterslev J, Steinbrüchel DA, Gluud C. Clinical outcomes in randomized trials of off- vs. on-pump coronary artery bypass surgery: systematic review with meta-analyses and trial sequential analyses. Eur Heart J. 2008;29:2601-16

17. Shroyer AL, Grover FL, Hattler B, Collins JF, McDonald GO, Kozora E, et al; Veterans Affairs Randomized On/Off Bypass (ROOBY) Study Group. Onpump versus off-pump coronary-artery bypass surgery. N Engl J Med. 2009; 361:1827-37.

18. Racz MJ, Hannan EL, Isom OW, Subramanian VA, Jones RH, Gold JP, et al. A comparison of short- and long-term outcomes after off-pump and on-pump coronary artery bypass graft surgery with sternotomy. J Am Coll Cardiol. 2004;43: 557-64.

19. Hattler B, Messenger JC, Shroyer AL, Collins JF, Haugen SJ, Garcia JA, et al; Veterans Affairs Randomized On/Off Bypass (ROOBY) Study Group. OffPump coronary artery bypass surgery is associated with worse arterial and saphenous vein graft patency and less effective revascularization: results from the Veterans Affairs Randomized On/Off Bypass (ROOBY) trial. Circulation. 2012; 125:2827-35.

20. Alamanni F, Dainese L, Naliato M, Gregu S, Agrifoglio M, Polvani GL, et al; Monzino OPCAB Investigators. On- and off-pump coronary surgery and perioperative myocardial infarction: an issue between incomplete and extensive revascularization. Eur J Cardiothorac Surg. 2008;34:118-26.

21. Khan NE, De Souza A, Mister R, Flather M, Clague J, Davies S, et al. A randomized comparison of off-pump and on-pump multivessel coronary-artery bypass surgery. N Engl J Med. 2004;350:21-8.

22. Houlind K, Fenger-Grøn M, Holme SJ, Kjeldsen BJ, Madsen SN, Rasmussen BS, et al; DOORS Study Group. Graft patency after off-pump coronary artery bypass surgery is inferior even with identical heparinization protocols: Results from the Danish On-pump Versus Off-pump Randomization Study (DOORS). J Thorac Cardiovasc Surg. 2014;148:1812-9.e2.

23. Sousa Uva M, Cavaco S, Oliveira AG, Matias F, Silva C, Mesquita A, et al. Early graft patency after off-pump and on-pump coronary bypass surgery: a prospective randomized study. Eur Heart J. 2010;31:2492-9.

24. Hannan EL, Wu C, Smith CR, Higgins RS, Carlson RE, Culliford AT, et al. Ofpump versus on-pump coronary artery bypass graft surgery: differences in short-term outcomes and in long-term mortality and need for subsequent revascularization. Circulation. 2007;116:1145-52.

25. Calafiore AM, Teodori G, Di Giammarco G, Vitolla G, Maddestra N, Paloscia L, et al. Multiple arterial conduits without cardiopulmonary bypass: early angiographic results. Ann Thorac Surg. 1999;67:450-6.

26. Puskas JD, Thourani VH, Marshall JJ, Dempsey SJ, Steiner MA, Sammons BH, et al. Clinical outcomes, angiographic patency, and resource utilization in 200 consecutive off-pump coronary bypass patients. Ann Thorac Surg. 2001;71: 1477-83; discussion 1483-4.

27. Geneau R, Stuckler D, Stachenko S, McKee M, Ebrahim S, Basu S, et al. Raising the priority of preventing chronic diseases: a political process. Lancet. 2010;376: 1689-98.

28. Schilling UM. Cost awareness among Swedish physicians working at the emergency department. Eur J Emerg Med. 2009;16:131-4.

29. Seccareccia F, Perucci CA, D'Errigo P, Arcà M, Fusco D, Rosato S, et al; Research Group of the Italian CABG Outcome Study. The Italian CABG Outcome Study: short-term outcomes in patients with coronary artery bypass graft surgery. Eur J Cardiothorac Surg. 2006;29:56-62; discussion 62-4.

30. D'Errigo P, Tosti ME, Fusco D, Perucci CA, Seccareccia F, Research group, Italian CABG Outcome Study. Use of hierarchical models to evaluate performance of cardiac surgery centres in the Italian CABG outcome study. BMC Med Res Methodol. 2007;7:29.

31. D'Errigo P, Seccareccia F, Rosato S, Manno V, Badoni G, Fusco D, et al. Comparison between an empirically derived model and the EuroSCORE system in the evaluation of hospital performance: the example of the Italian CABG Outcome Project. Eur J Cardiothorac Surg. 2008;33:325-33. 
32. Rosato S, D'Errigo P, Badoni G, Fusco D, Perucci CA, Seccareccia F. [Comparison between administrative and clinical databases in the evaluation of cardiac surgery performance]. G Ital Cardiol (Rome). 2008;9:569-78. Italian.

33. Putter H, Fiocco M, Geskus RB. Tutorial in biostatistics: competing risks and multi-state models. Stat Med. 2007;26:2389-430.

34. Pintilie M. Competing risks: a practical perspective. Chichester (UK): John Wiley \& Sons; 2006

35. Barili F, Barzaghi N, Cheema FH, Capo A, Jiang J, Ardemagni E, et al. An original model to predict intensive care unit length-of stay after cardiac surgery in a competing risk framework. Int J Cardiol. 2013;168:219-25.

36. Borst C, Gründeman PF. Minimally invasive coronary artery bypass grafting: an experimental perspective. Circulation. 1999;99:1400-3.
37. Royston D. The inflammatory response and extracorporeal circulation. J Cardiothorac Vasc Anesth. 1997;11:341-54.

38. Ascione R, Lloyd CT, Underwood MJ, Lotto AA, Pitsis AA, Angelini GD. Inflammatory response after coronary revascularization with or without cardiopulmonary bypass. Ann Thorac Surg. 2000;69:1198-204.

39. Lamy A, Devereaux PJ, Prabhakaran D, Taggart DP, Hu S, Paolasso E, et al. Effects of off-pump and on-pump coronary-artery bypass grafting at 1 year. $N$ Engl J Med. 2013;368:1179-88.

Key Words: surgery, risk factors, follow-up studies, revascularization

\title{
EDITORIAL COMMENTARY
}

\section{The emperor's new clothes}

\author{
Richard Lee, MD, MBA
}

From the Center for Comprehensive Cardiovascular Care, Saint Louis University, Saint Louis, Mo.

Disclosures: Author has nothing to disclose with regard to commercial support.

Received for publication July 17, 2015; accepted for publication July 17, 2015; available ahead of print Aug 28, 2015.

Address for reprints: Richard Lee, MD, MBA, Center for Comprehensive Cardiovascular Care, Saint Louis University, 3635 Vista Ave, DT 13th Fl, Saint Louis, MO 63310 (E-mail: rlee@slu.edu).

J Thorac Cardiovasc Surg 2015;150:909-10

$0022-5223 / \$ 36.00$

Copyright (c) 2015 by The American Association for Thoracic Surgery

http://dx.doi.org/10.1016/j.jtcvs.2015.07.092

The fairy tale "The Emperor's New Clothes" ${ }^{1}$ has origins that can be traced back as far as Aesop. However, in the version most of us are familiar with, weavers appeal to their emperor's vanity and inflated ego by describing a nonexistent new suit as invisible to those who are unfit for their positions, stupid, or incompetent. It takes a child unconcerned with position in society to point out that the emperor is naked.

In "Impact of off-pump coronary artery bypass grafting on long-term percutaneous coronary interventions," Barili and colleagues ${ }^{2}$ analyze data from the Predicting Long-Term Outcomes after Isolated Coronary Artery Bypass Surgery project, which included 11,021 patients. After adjustment, they found that off-pump coronary bypass grafting (OPCABG) demonstrated a $42 \%$ higher risk for subsequent percutaneous coronary intervention than on-pump coronary artery bypass grafting (ONCABG) without a difference in mortality. One of the distinguishing aspects of this article is longer follow-up than other articles - up to 8 years.

There seems to be growing evidence that in large populations, the results of OPCABG may be inferior to ONCABG, especially in terms of complete revascularization and graft patency. I recently wrote a commentary for this journal that cited commentaries by $\mathrm{Sabik}^{3}$ and Lazar ${ }^{4}$ suggesting that ONCABG be the preferred approach to surgical

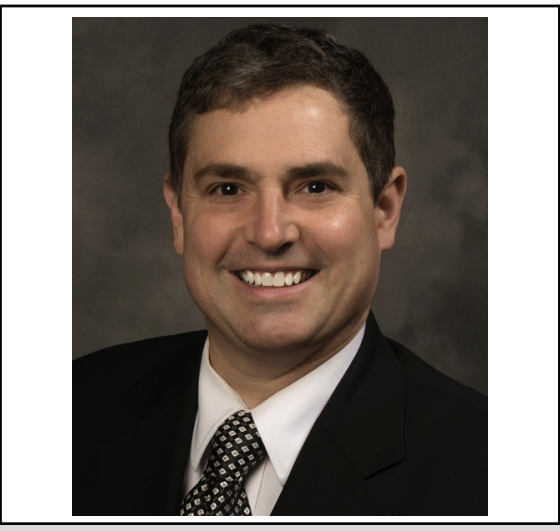

Richard Lee, MD, MBA

Central Message

This article addresses the emerging evidence for higher repeat revascularization in patients undergoing OPCABG.

See Article page 902.

revascularization. Even some OPCABG proponents, such as Smith, ${ }^{5}$ have acknowledged that OPCABG may lead to higher early graft failure.

Surgeons have cited repeat revascularization as the Achilles' heel of percutaneous coronary intervention. In fact, without repeat revascularization as a hard end point and part of the major composite end point, it is unlikely that the SYNTAX trial or any future stent versus CABG comparison will favor surgical revascularization. ${ }^{6} \mathrm{We}$ cannot have it both ways. We have to see repeat myocardial 


\section{APPENDIX E1. CARDIAC SURGERY CENTERS OF THE ITALIAN-CABG PROJECT ${ }^{29}$}

Casa di Cura 'Villa Maria Pia,' Torino

Azienda Ospedaliera Mauriziano Umberto I, Torino

Azienda Ospedaliera Santa Croce e Carle, Cuneo

Nuova Casa di Cura Città di Alessandria-Gruppo Progess, Alessandria

Ospedale Civile S. Antonio E Biagio, Alessandria

Azienda Ospedaliera Niguarda Ca' Granda, Milano

Azienda Ospedaliera San Gerardo-Università Degli

Studi di Milano-Bicocca, Monza (Milano)

Casa Di Cura Poliambulanza, Brescia

Clinica San Rocco Franciacorta Ome, Brescia

Istituto Clinico Humanitas, Rozzano (Milano)

Istituto Policlinico San Donato, San Donato Milanese (Milano)

Ospedale 'L. Sacco,' Milano

Ospedale Civile, Legnano (Milano)

Ospedale di Circolo e Fondazione Macchi, Varese

Ospedale San Raffaele, Milano

Policlinico Di Monza—Gruppo Progess, Monza (Milano)

Presidio Ospedaliero 'C. Poma,' Mantova

Università degli Studi—IRCCS—Policlinico 'S. Matteo,' Pavia

Università degli Studi Di Milano-Cattedra Di Cardiochirurgia, Milano

Istituto Clinico Sant'Ambrogio, Milano

Università Di Milano-Ospedale Maggiore Policlinico IRCCS, Milano

Casa Di Cura Policlinico Multimedica, Sesto S. Giovanni (Milano)

Casa Di Cura Cliniche Gavazzeni Spa, Bergamo

Ospedali Riuniti di Bergamo, Bergamo

Azienda Ospedaliera Spedali Civili Di Brescia, Brescia

Ospedale S. Chiara, Trento

Ospedale 'San Bortolo,' Vicenza

Ospedale Civile, Mirano (Venezia)

Ospedale Civile Maggiore, Verona

Ospedale S. Maria Dei Battuti, Treviso

Ospedale Umberto I, Mestre (Venezia)

Università Di Padova—Policlinico, Padova

Azienda Ospedaliera 'S. Maria Della Misericordia,' Udine

Nuovo Polo Cardiologico-Ospedale di Cattinara, Trieste

Ospedale San Martino, Genova
Università degli Studi di Genova-Ospedale San Martino, Genova

Villa Azzurra, Rapallo (Genova)

Azienda Ospedaliera Universitaria di Parma, Parma

Casa di Cura 'Villa Torri' Spa, Bologna

Casa di Cura Villa Maria Cecilia, Cotignola (RA)

Casa di Cura Villa Salus, Reggio Emilia

Hesperia Hospital S.r.l., Modena

Università Degli Studi Di Bologna-Policlinico S. Orsola, Bologna

Azienda Ospedaliera Universitaria Senese-Policlinico Le Scotte, Siena

Policlinico di Careggi-Firenze

Clinica 'Villa Maria Beatrice,' Firenze

Ospedale 'G. Pasquinucci' Creas IFC-CNR, Massa

Azienda Ospedaliera 'S. Maria,' Terni

Ospedale Silvestrini, Perugia

Ospedale 'G.M. Lancisi,' Ancona

Azienda Complesso Ospedaliero 'San Filippo Neri,' Roma

Azienda Ospedale S. Camillo Forlanini, Roma

European Hospital-Università Tor Vergata, Roma

Policlinico Umberto I, Roma

Azienda Ospedaliera Sant' Andrea, Roma

Università Cattolica Del Sacro Cuore-Policlinico 'A. Gemelli,' Roma

Università Di Roma 'Campus Bio-Medico', Roma

Ospedale Giuseppe Mazzini, Teramo

Università 'Gabriele D'Annunzio'-Ospedale 'San Camillo De Lellis,' Chieti

Azienda Ospedaliera Monaldi, Napoli

Azienda Ospedaliera Moscati, Avellino

Azienda Ospedaliera S. Sebastiano, Caserta

Lonobile T, De Bellis A, Casa di Cura San Michele, Maddaloni-CE

Clinica Mediterranea, Napoli

Casa di Cura 'S. Lucia', S. Giuseppe Vesuviano-NA

Ospedale San Leonardo, Salerno

Casa di Cura Montevergine, Mercogliano-AV

Azienda Ospedaliera 'Vito Fazzi,' Lecce

Casa di Cura Città Di Lecce, Lecce

Casa di Cura S. Maria, Bari

Casa di Cura Villa Bianca, Bari

Ospedale Policlinico Consorziale, Bari

Villa Anthea, Bari 
Ospedale S. Carlo, Potenza

S. Anna Hospital, Catanzaro

Azienda Ospedaliera Papardo, Messina

Azienda Ospedaliera Vittorio Emanuele-Ferrarotto-

S. Bambino-Università, Catania

Casa di Cura Centro Cuore Morgagni, Pedara-CT

Villa 'Maria Eleonora,' Palermo

Università degli Studi 'Magna Graecia'-Azienda Ospedaliera Mater Domini, Catanzaro

Azienda di rilievo nazionale e di alta specializzazione Ospedale Civico e Benfratelli, Palermo

Azienda Ospedaliera 'G. Brotzu,' Cagliari

\section{APPENDIX E2. CARDIAC SURGERY CENTERS OF THE ITALIAN-CABG PROJECT ${ }^{31}$}

Casa di Cura Villa Maria Pia Torino

Istituto Clinico Sant'Ambrogio, Milano

Clinica San Rocco di Franciacorta Oma (BS)

Presidio Ospedaliero C. Poma Mantova

A.O. San Gerardo-Università degli Studi di MilanoBicocca Monza (MI)

Ospedale San Raffaele Milano
Istituto Clinico Humanitasa Rozzano (MI)

Nuovo Polo Cardiologico-Ospedale di Cattinara Trieste

Villa Azzurra Rapallo (GE)

Ospedale San Martino-Divisione di Cardiochirurgia Genova

Casa di Cura Villa Salus Reggio Emilia

Hesperia Hospital Srl Modena

Villa Maria Cecilia Hospital Cotignola (RA)

Clinica Villa Maria Beatrice Firenze

A.O. Santa Maria Terni

A.O. San Camillo-Forlanini Roma

Ospedale San Filippo Neri Roma

Università Campus Bio-Medico Roma

Casa di Cura San Michele Maddaloni (CE)

Casa di Cura Montevergine Mercogliano (AV)

A.O. San Sebastiano, Caserta

Anthea Hospital Bari

Casa di Cura Città di Lecce Lecce

Villa Maria Eleonora Palermo

A.O. Papardo, Messina

Clinica Pineta Grande Castel Volturno (CE) 
PROPENSITY SCORE DISTRIBUTION
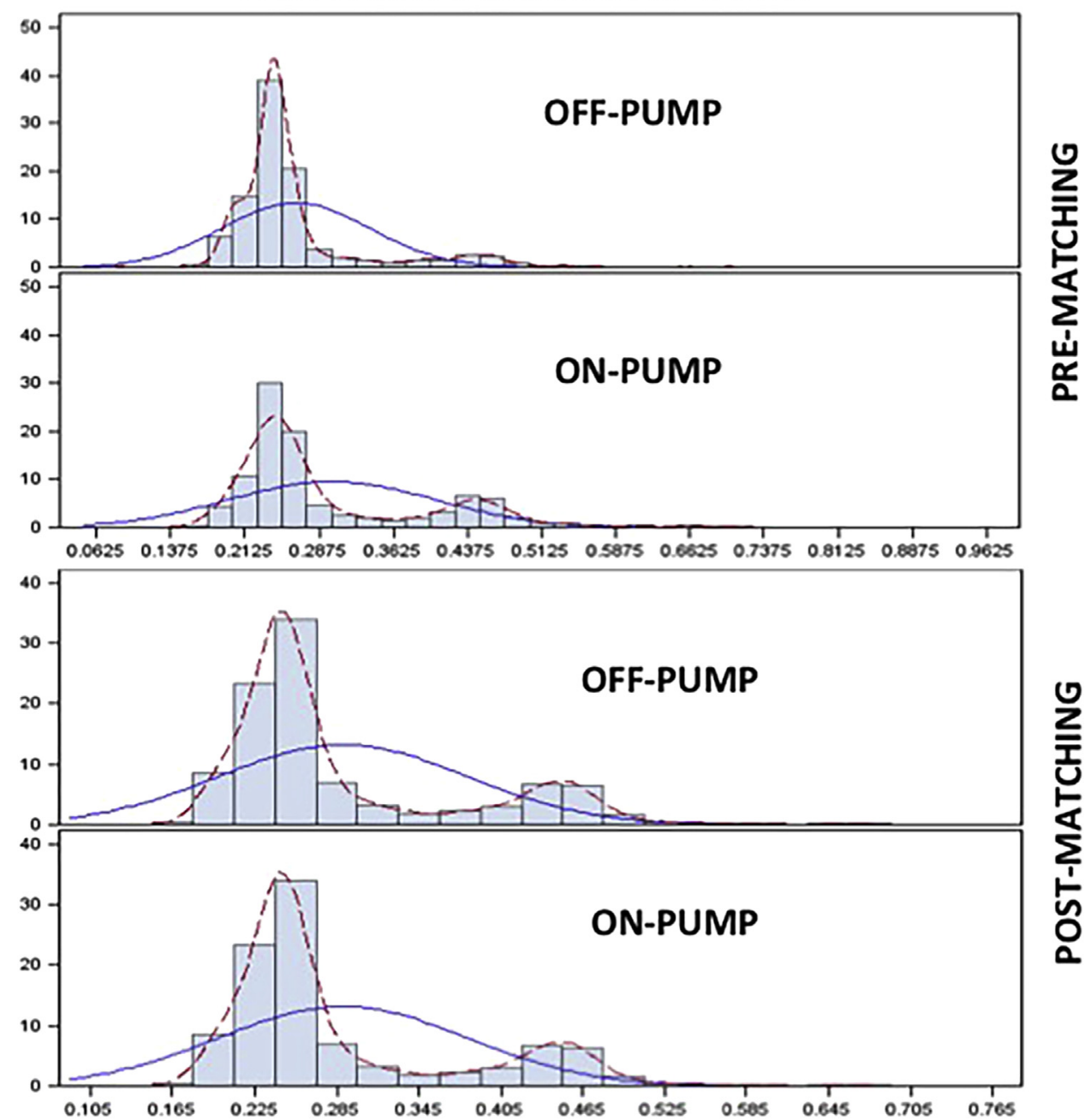

FIGURE E1. Propensity score distributions before and after matching. After matching, the propensity score distribution was similar in the off-pump and on-pump groups.

KAPLAN-MEIER ESTIMATES OF LONG-TERM SURVIVAL OF THE TWO MATCHED GROUPS

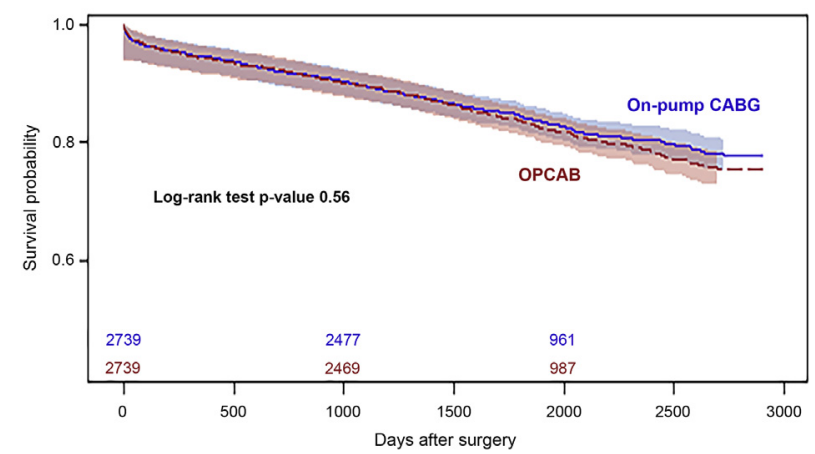

FIGURE E2. Kaplan-Meier estimates of survival in the matched groups. The difference between OPCAB and on-pump CABG curves was not significant (log-rank $P>.05$ ). $C A B G$, Coronary artery bypass grafting; $O P C A B$, off-pump coronary artery bypass grafting. 
CUMULATIVE INCIDENCE FUNCTION OF REHOSPITALIZATION FOR PCI OF THE TWO MATCHED GROUPS

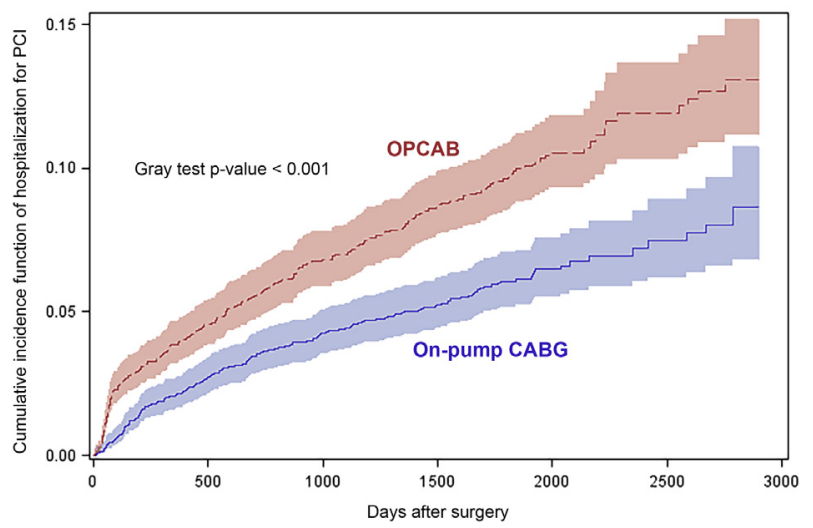

FIGURE E3. Cumulative incidence functions of the first hospitalization for PCI in the matched groups, with death as a competing risk. The difference between $\mathrm{OPCAB}$ and on-pump CABG was significant (Gray test $P<.001)$. $P C I$, Percutaneous coronary intervention; $O P C A B$, off-pump coronary artery bypass grafting; $C A B G$, coronary artery bypass grafting. 
TABLE E1. Odds ratios and $95 \%$ confidence interval of the adjusted logistic regression model for predicting in-hospital mortality

\begin{tabular}{lccr}
\hline \multicolumn{1}{c}{ Variable } & OR & 95\% CI of OR & $\boldsymbol{P}$ value \\
\hline On-pump CABG & 1.23 & $0.89-1.72$ & .141 \\
Female sex & 1.35 & $0.96-1.86$ & .090 \\
Age, y & 1.07 & $1.06-1.10$ & $<.001$ \\
Left ventricular ejection fraction $<30 \%$ & 2.60 & $1.44-4.45$ & $<.001$ \\
Cardiogenic shock & 6.73 & $3.37-13.10$ & $<.001$ \\
Dialysis & 5.54 & $2.45-11.56$ & $<.001$ \\
Chronic pulmonary disease & 1.77 & $1.18-2.58$ & .006 \\
Creatinine $>$ 2 mg/dL & 2.20 & $1.37-3.41$ & .002 \\
Unstable angina & 1.67 & $1.22-2.27$ & .001 \\
Recent myocardial infarction & 1.52 & $1.11-2.06$ & .005 \\
Previous CABG & 3.42 & $1.81-5.98$ & $<.001$ \\
Emergency status & 3.07 & $1.89-4.84$ & $<.001$ \\
\hline
\end{tabular}

$O R$, Odds ratio; $C I$, confidence interval; $C A B G$, coronary artery bypass grafting.

TABLE E2. Crude mortalities and occurrence of the first percutaneous coronary intervention rate estimates

\begin{tabular}{|c|c|c|c|c|c|c|}
\hline & $30 \mathrm{~d}$ & $100 \mathrm{~d}$ & $1 \mathbf{y}$ & $3 y$ & $5 y$ & $8 y$ \\
\hline \multicolumn{7}{|l|}{ First PCI } \\
\hline OPCAB & $0.3(0.1-0.5)$ & $2.2(1.7-2.8)$ & $3.7(3.1-4.4)$ & $5.6(4.8-6.4)$ & $9.8(8.8-11.0)$ & $14.3(12.6-16.0)$ \\
\hline On-pump CABG & $0.1(0.1-0.3)$ & $0.7(0.5-0.9)$ & $2.3(2.0-2.7)$ & $3.8(3.4-4.2)$ & $6.8(6.3-7.4)$ & $12.0(10.8-13.3)$ \\
\hline All & $0.2(0.1-0.3)$ & $1.1(0.9-1.3)$ & $2.7(2.4-3.0)$ & $4.3(3.9-4.7)$ & $7.6(7.2-8.2)$ & $12.6(11.6-13.6)$ \\
\hline \multicolumn{7}{|l|}{ Mortality } \\
\hline OPCAB & $2.2(1.7-2.7)$ & $3.6(3.0-4.3)$ & $5.6(4.9-6.5)$ & $7.8(6.9-8.8)$ & $16.1(14.8-17.5)$ & $23.5(21.7-25.3)$ \\
\hline On-pump CABG & $2.0(1.7-2.3)$ & $3.0(2.6-3.4)$ & $4.5(4.1-5.0)$ & $6.3(5.7-6.8)$ & $13.0(12.2-13.7)$ & $20.2(19.1-21.3)$ \\
\hline All & $2.1(1.8-2.3)$ & $3.2(2.8-3.5)$ & $4.8(4.4-5.2)$ & $6.7(6.2-7.2)$ & $13.8(13.2-14.5)$ & $21.1(20.2-22.1)$ \\
\hline
\end{tabular}


TABLE E3. Hazard ratios of the adjusted Cox semiparametric regression model for predicting long-term mortality

\begin{tabular}{lrcr}
\hline \multicolumn{1}{c}{ Variable } & HR & 95\% CI HR & $\boldsymbol{P}$ value \\
\hline On-pump CABG & .96 & $.87-1.06$ & .407 \\
Age (y) & 1.07 & $1.07-1.08$ & $<.001$ \\
Left ventricular ejection fraction $<30 \%$ & 2.13 & $1.72-2.64$ & $<.001$ \\
Hemodynamic instability & 1.20 & $1.00-1.44$ & .049 \\
Cardiogenic shock & 1.88 & $1.24-2.83$ & .002 \\
Diabetes & 1.42 & $1.29-1.56$ & $<.001$ \\
Cirrhosis & 3.97 & $2.25-7.02$ & $<.001$ \\
Dialysis & 2.99 & $2.23-4.00$ & $<.001$ \\
Recent ventricular arrhythmia & 1.27 & $1.00-1.61$ & .047 \\
Chronic pulmonary disease & 1.54 & $1.36-1.75$ & $<.001$ \\
Creatininemia $>2$ mg/dL & 1.95 & $1.67-2.28$ & $<.001$ \\
Extracardiac arteriopathy & 1.39 & $1.25-1.54$ & $<.001$ \\
Previous stroke & 1.41 & $1.16-1.72$ & $<.001$ \\
Angina & 1.10 & $.99-1.21$ & .072 \\
Previous CABG & 1.51 & $1.16-1.96$ & .002 \\
Pulmonary hypertension & 1.73 & $.98-3.04$ & .059 \\
Cancer & 1.81 & $1.35-2.43$ & $<.001$ \\
\hline
\end{tabular}

$H R$, Hazard ratio; $C I$, confidence interval; $C A B G$, coronary artery bypass grafting.

TABLE E4. Baseline characteristics of paired propensity-matched off-pump and on-pump coronary artery bypass grafting groups, with the prematch and postmatch standardized difference

\begin{tabular}{|c|c|c|c|c|}
\hline \multirow[b]{2}{*}{ Variables } & \multicolumn{4}{|c|}{ Postmatching data } \\
\hline & On-pump CABG & OPCAB & $P$ value & Standardized difference \\
\hline Age $(y$, mean $\pm S E)$ & $67.6(9.1 \%)$ & $67.5(10.0 \%)$ & .59 & -0.013 \\
\hline Previous cardiac surgery excluding CABG (No. and \%) & $30(1.1 \%)$ & $30(1.1 \%)$ & $>.999$ & 0.000 \\
\hline Hemodynamic instability* (No. and \%) & $187(6.8 \%)$ & $181(6.6 \%)$ & .71 & -0.009 \\
\hline Cardiogenic shock (No. and \%) & $10(0.4 \%)$ & $12(0.4 \%)$ & .65 & 0.012 \\
\hline Diabetes (requiring drug treatment; No. and \%) & $876(32.0 \%)$ & $912(33.3 \%)$ & .29 & 0.028 \\
\hline Cirrhosis (No. and \%) & $8(0.3 \%)$ & $7(0.3 \%)$ & .80 & -0.007 \\
\hline Dialysis (No. and \%) & $25(0.9 \%)$ & $27(1.0 \%)$ & .78 & 0.008 \\
\hline Neurologic dysfunction $\dagger$ (No. and \%) & $58(2.1 \%)$ & $60(2.2 \%)$ & .85 & 0.005 \\
\hline Pulmonary hypertension $\dagger$ (No. and \%) & $17(0.6 \%)$ & $13(0.5 \%)$ & .47 & -0.020 \\
\hline Recent ventricular arrhythmia $\ddagger$ (No. and \%) & $65(2.4 \%)$ & $56(2.0 \%)$ & .40 & -0.022 \\
\hline Chronic pulmonary disease $\dagger$ (No. and \%) & $369(13.5 \%)$ & $370(13.5 \%)$ & .95 & 0.001 \\
\hline Creatininemia ( $>2 \mathrm{mg} / \mathrm{dL}$; No. and $\%)$ & $160(5.8 \%)$ & $138(5.0 \%)$ & .13 & -0.035 \\
\hline Cancer (No. and \%) & $29(1.1 \%)$ & $39(1.4 \%)$ & .22 & 0.033 \\
\hline Extracardiac arteriopathy $\dagger$ (No. and \%) & $613(22.4 \%)$ & $606(22.1 \%)$ & .81 & -0.006 \\
\hline Previous stroke (No. and \%) & $115(4.2 \%)$ & $111(4.1 \%)$ & .78 & -0.007 \\
\hline Unstable angina (No. and \%) & $795(29.0 \%)$ & $770(28.1 \%)$ & .44 & -0.020 \\
\hline Recent myocardial infarction $\dagger$ (No. and \%) & $640(23.4 \%)$ & $627(22.9 \%)$ & .56 & -0.011 \\
\hline Previous CABG (No. and \%) & $66(2.4 \%)$ & $71(2.6 \%)$ & .64 & 0.012 \\
\hline Emergency status of operation $\dagger$ (No. and \%) & $110(4.0 \%)$ & $113(4.1 \%)$ & .84 & 0.006 \\
\hline Female sex (No. and \%) & $568(20.7 \%)$ & $554(20.2 \%)$ & .61 & -0.013 \\
\hline Left ventricular ejection fraction (No and \%) & & & .84 & 0.032 \\
\hline $30 \%-50 \%$ & $635(23.2 \%)$ & $645(23.5 \%)$ & & \\
\hline$<30 \%$ & $65(2.4 \%)$ & $73(2.7 \%)$ & & \\
\hline
\end{tabular}

$C A B G$, Coronary artery bypass grafting; $O P C A B$, off-pump coronary artery bypass grafting; $S E$, standard error. *Preoperative inotropic support or intra-aortic balloon pump. $\dagger$ As defined by the euroSCORE. $\ddagger$ Preoperative recurrent ventricular tachycardia or ventricular fibrillation. 